\title{
Impact of induction chemoradiotherapy on pulmonary function after lobectomy for lung cancer
}

\author{
Hiroaki Nomori, MD, ${ }^{\mathrm{a}}$ Atsushi Shiraishi, MD, ${ }^{\mathrm{b}}$ Yue Cong, MD, ${ }^{\mathrm{a}}$ Kazufusa Shoji, MD, \\ Masafumi Misawa, MD, ${ }^{\mathrm{d}}$ Hiroshi Sugimura, MD, ${ }^{\mathrm{a}}$ and $\mathrm{Yu}$ Oyama, $\mathrm{MD}^{\mathrm{e}}$
}

\section{ABSTRACT}

Objective: Our study aim was to determine whether there are differential changes in whole-lung and regional lung functions after lobectomy for lung cancer between propensity score-matched patients treated with and without induction chemoradiotherapy, by using single-photon emission computed tomography lung perfusion.

Methods: This study was a retrospective matched cohort study of consecutively acquired data. Pulmonary function test and perfusion scintigraphy were conducted before lobectomy and 6 months after lobectomy in patients treated with induction therapy $(n=72)$ and in those not treated $(n=170)$, for measuring functional changes of whole lung, contralateral lung, and lobes. After exact matching on resected lobe site, propensity scores for age, smoking status, preoperative pulmonary functions, and predicted postoperative pulmonary function were used to match the groups.

Results: After the matching, 46 patients were selected from the groups. Standardized mean differences of the 5 matched variables were $<0.1$. Whole lung function significantly decreased after lobectomy in the induction therapy group than in the noninduction therapy group $(P<.001)$. Although ipsilateral preserved lobe function before surgery was not different between the groups $(P=.33)$, postoperative value was significantly lower in the induction therapy group than in the noninduction therapy group $(P<.001)$. Although both groups showed a significant increase of contralateral lung function after lobectomy $(P<.01)$, the increases were not significantly different between the groups $(P=.81)$.

Conclusions: Induction chemoradiotherapy was associated with reduced pulmonary function after lobectomy because of a decrease in ipsilateral preserved lobe function, which could be caused by the chronic effects of the induction chemoradiotherapy. (J Thorac Cardiovasc Surg 2018;155:2129-37)

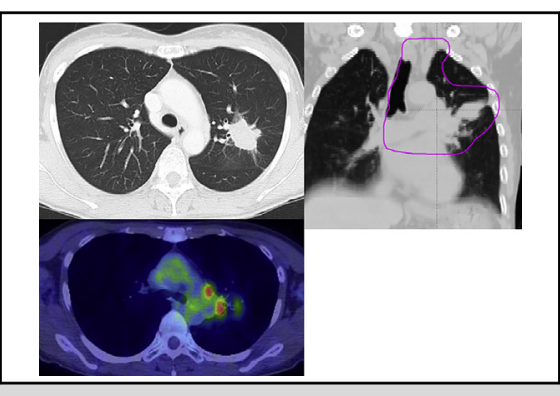

The field received 20 Gy or more (purple line) for left upper lobe cT2aN2M0 cancer.

\section{Central Message}

Induction chemoradiotherapy for lung cancer was associated with reduced pulmonary function after lobectomy because of a decrease of ipsilateral lobe function caused by the chronic effect of chemoradiotherapy.

\section{Perspective}

Induction chemoradiotherapy for lung cancer was associated with reduced pulmonary function after lobectomy because of a decrease of ipsilateral preserved lobe function caused by the chronic effect of chemoradiotherapy. Although induction therapy as well as noninduction therapy groups showed a significant increase of postoperative contralateral lung function, the increases were not different between the groups.

See Editorial Commentary page 2138.

See Editorial page 2127.
Induction chemoradiotherapy (ICRT) is currently used for surgical cases of locally advanced non-small-cell lung cancer (NSCLC), of which outcomes have been reportedly as satisfactory. ${ }^{1-5}$ However, ICRT might cause an adverse

\footnotetext{
From the Departments of ${ }^{\mathrm{a}}$ Thoracic Surgery, ${ }^{\mathrm{b}}$ Emergency and Trauma Center, ${ }^{\mathrm{c}}$ Radiology, ${ }^{\mathrm{d}}$ Pulmonary Medicine, and ${ }^{\mathrm{e}}$ Medical Oncology, Kameda Medical Center, Kamogawa City, Chiba, Japan.

Received for publication May 10, 2017; revisions received Dec 11, 2017; accepted for publication Dec 16, 2017; available ahead of print Feb 1, 2018.

Address for reprints: Hiroaki Nomori, MD, Department of General Thoracic Surgery, Kameda Medical Center, 929 Higashi-cho, Kamogawa City 296-8602, Chiba, Japan (E-mail: hnomori@qk9.so-net.ne.jp). $0022-5223 / \$ 36.00$

Copyright (c) 2017 by The American Association for Thoracic Surgery https://doi.org/10.1016/j.jtcvs.2017.12.081
}

effect on postoperative pulmonary function due to damage to lung tissue. Although ICRT has been reported to decrease diffusion capacity of the lung for carbon monoxide (DLCO) before surgery, ${ }^{6,7}$ there have been few reports examining the effects of ICRT on postoperative pulmonary function. Perentes et al and Cerfolio et al

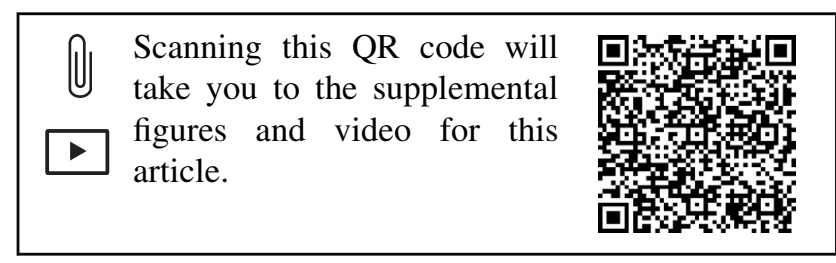




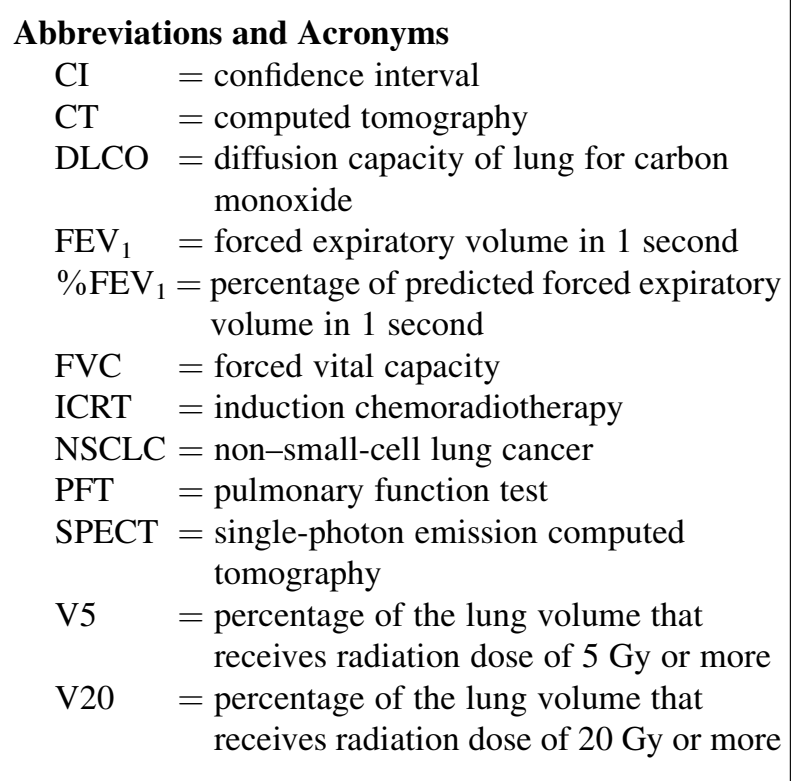

reported the decrease of pulmonary function or DLCO after ICRT, but they did not examine the pulmonary function after surgery. ${ }^{6,7}$ Although Margaritora et al described that pulmonary function decreased after ICRT followed by surgery, ${ }^{8}$ they did not compare the postoperative function between the patients treated with and without ICRT.

Because ICRT damages normal lung tissue around the tumor, the effects of ICRT on postoperative pulmonary function should be examined not only in whole lung but also in regional lung, such as ipsilateral preserved lobe and contralateral lung. To measure the regional lung function, the following methods have been reported: (1) calculation of the number of "subsegments," (2) computed tomography (CT) volumetry, ${ }^{10}$ and (3) single-photon emission CT (SPECT) lung perfusion. ${ }^{11}$ Of these, SPECT lung perfusion is reported to be the most accurate method for measuring regional lung function. ${ }^{12}$ Using SPECT perfusion, the regional function can be calculated using the following formula: (the radioactivity of regional lung/the radioactivity of whole lung) $\times$ whole lung function measured using a pulmonary function test (PFT).

In the present study, to clarify the effect of ICRT on postoperative changes of whole-lung and regional lung functions, we conducted PFT with spirometry and SPECT lung perfusion before as well as after lobectomy, and compared the data between patients treated with and without ICRT using propensity score matching.

\section{METHODS \\ Study Design}

The study was a retrospective matched cohort study of consecutively acquired data. The examination for PFT with spirometry and perfusion scintigraphy with SPECT/CT before and after major lung resection was approved in
2012 by the Ethics Committee of Kameda Medical Center (approval number: 12-085), which is an educational and cancer designated hospital, where more than 150 patients with lung cancer per year are treated with surgery.

\section{Data Source}

Between January 2013 and January 2017, 452 patients who were treated with major lung resection (ie, lobectomy, segmentectomy, or pneumonectomy), were planned to receive PFT with spirometry and perfusion SPECT/CT before and after surgery. The postoperative PFT and perfusion SPECT/CT were conducted 6 months after surgery, because we have previously reported that the postoperative pulmonary function continues to recover until 6 months after surgery and becomes stable after that. ${ }^{13,14}$

\section{Eligibility for the Present Study}

The inclusion criteria for preoperative PFT and SPECT/CT in the present study were all patients with lung cancer treated with lobectomy. The exclusion criteria for postoperative examinations were as follows: patients with tumor recurrence, pulmonary complications after surgery, and postoperatively another disease that could affect pulmonary function. The exclusion criteria for patients, who were examined pre- and postoperatively, were as follows: previous lung surgery, additional lung resection of another lobe during surgery, rib resection, phrenic nerve resection, and preoperative radiation therapy alone or chemotherapy alone. Patients treated with postoperative adjuvant chemotherapy at 6 months after surgery were excluded to eliminate the effect of chemotherapy on postoperative pulmonary function. The aim of the study was explained to all patients, which was to predict and evaluate postoperative whole- and regional pulmonary function using PFT and SPECT lung perfusion before as well as after surgery. All patients provided written informed consent for the study.

\section{Outcome}

The primary outcome for the study was the postoperative changes of whole-lung function. The secondary outcomes included the postoperative changes of ipsilateral preserved lobe and contralateral lung functions.

\section{ICRT}

In accordance with the Guidelines for Lung Cancer published by the Japan Lung Cancer Society, ${ }^{15}$ the Lung Cancer Board of our hospital established a protocol for ICRT followed by surgery for locally advanced NSCLC in October 2012, which was approved by our institutional ethics committee in 2014 (approval number: 14-005). The inclusion criteria for ICRT were as follows: (1) T3 or T4 stage determined using CT as well as magnetic resonance imaging, (2) N2 stage confirmed using endobronchial ultrasound-guided transbronchial needle aspiration and/or fluorodeoxyglucose-positron emission tomography, and (3) N1 stage with metastatic lymph nodes invading the hilar bronchus or vessels with intent to avoid pneumonectomy. The ICRT was concurrent chemoradiotherapy (ie, 2 cycles of a platinum doublet regimen: cisplatin $40 \mathrm{mg} / \mathrm{m}^{2}+$ docetaxel $40 \mathrm{mg} / \mathrm{m}^{2}$ [day $1,8,29,36$ ] or carboplatin (AUC2) + paclitaxel $40 \mathrm{mg} / \mathrm{m}^{2}$ [day 1, 8, 15, 22, 29, 36]) and radiotherapy. Radiation dose was usually 46 Gy for patients younger than 70 years and 40 Gy for older patients. All patients received an explanation of the aim of the ICRT, and consented to it with written informed consent. The grade of radiation pneumonitis was evaluated using the National Cancer Institute Common Terminology Criteria for Adverse Events version 4.0. The tumor, node, metastases classification was on the basis of the International Association for the Study of Lung Cancer. ${ }^{16}$

\section{Surgical Procedures}

All patients for the present study were treated with lobectomy with mediastinal lymph node dissection (as shown in Video 1). The mean duration from the end of ICRT to surgery was $49 \pm 11$ days $(95 \%$ confidence interval [CI], 47-53). Lobectomy for patients treated with ICRT was 


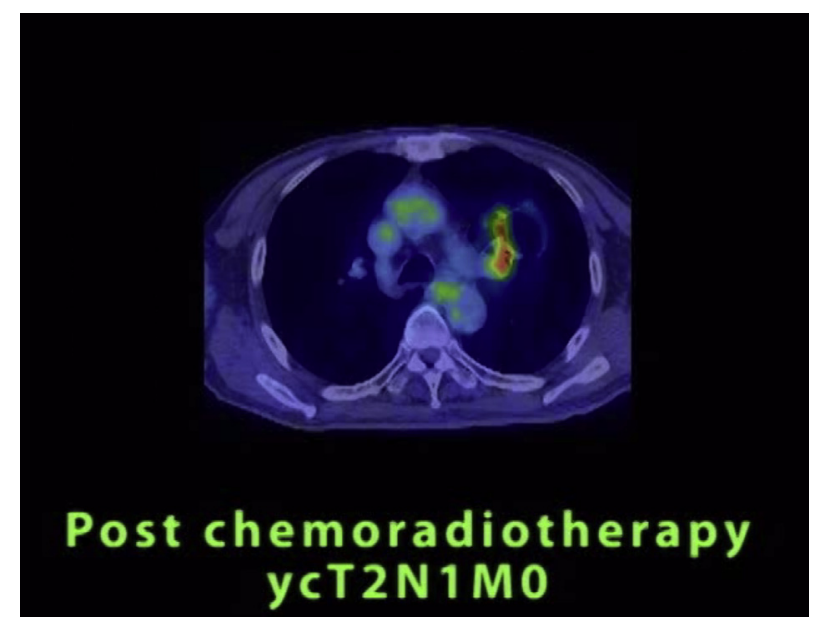

VIDEO 1. Left upper lobectomy after induction chemoradiotherapy. Video available at: http://www.jtcvsonline.org/article/S0022-5223(17) 33059-3/fulltext.

conducted usually with anterolateral thoracotomy as previously reported. ${ }^{17}$ Lobectomy for patients without ICRT was performed with limited thoracotomy or thoracoscopy as previously reported. ${ }^{18}$ We did not include the surgical approaches for propensity score-matching variables, because we previously reported that the difference of surgical approaches (ie, open thoracotomy vs thoracoscopic approaches), did not affect postoperative pulmonary function. ${ }^{12}$

\section{Postoperative Adjuvant Chemotherapy}

For the patients treated with ICRT, postoperative adjuvant chemotherapy was conducted, provided that the patients consented to it. For the patients not treated with ICRT, postoperative chemotherapy was conducted for pT2, pN1, or $\mathrm{pN} 2$ disease, provided that the patients consented.

\section{PFT}

Forced vital capacity (FVC) and forced expiratory volume in 1 second $\left(\mathrm{FEV}_{1}\right)$ were measured using a dry rolling-seal spirometer (Chest AC-8800; Chest Ltd, Tokyo, Japan). A percentage of predicted $\mathrm{FEV}_{1}(\%$ $\mathrm{FEV}_{1}$ ) was calculated by measured $\mathrm{FEV}_{1} /$ predicted $\mathrm{FEV}_{1} \times 100(\%)$. The predicted normal values of $\mathrm{FEV}_{1}$ were determined using the formulas of
Berglund et al. ${ }^{19}$ For patients in the ICRT group, PFT was performed at 3 time points (ie, before ICRT, after ICRT before surgery, and 6 months after surgery). For evaluating the preoperative pulmonary function in the ICRT group, the data after ICRT was used to match with SPECT lung perfusion, which was conducted after the ICRT. The DLCO was not routinely examined.

\section{SPECT Lung Perfusion}

SPECT lung perfusion was conducted before surgery and 6 months after surgery. For the patients treated with ICRT, preoperative SPECT perfusion was conducted after the ICRT to predict the postoperative whole-lung function by measuring the function of the resected lobe where the radiation therapy was performed. Each patient received $185 \mathrm{MBq}$ of ${ }^{99 \mathrm{~m}}$ Tc-macroaggregated human serum albumin (Daiichi Radioisotope Laboratories Ltd, Tokyo, Japan) intravenously administered. Perfusion scintigraphy and CT images were obtained using a SPECT scanner with a variable-angle digital gamma camera (E.CAM; Toshiba, Tokyo, Japan) and a 64-slice multidetector-row CT scanner (Aquilion One; Toshiba), respectively. SPECT and CT images were fused as SPECT/CT, using AZE Virtual Place Raijin software (AZE Ltd, Tokyo, Japan), as previously reported. ${ }^{20}$

\section{Evaluation of Postoperative Changes of Whole-Lung Function and Measurements of Functions of Ipsilateral Lobes and Contralateral Lung}

The postoperative change of whole-lung function was evaluated using the following formula: $\left(\% \mathrm{FEV}_{1}\right.$ in PFT after surgery $/ \% \mathrm{FEV}_{1}$ in PFT before surgery $\times 100(\%)$. Images of ipsilateral lobes and contralateral lung were traced on SPECT/CT, and the radioactivity was counted in each region. The $\% \mathrm{FEV}_{1}$ of regional functions was calculated as follows: $\% \mathrm{FEV}_{1}$ of resected lobe $=($ radioactivity of resected lobe/radioactivity of whole lung $) \times \% \mathrm{FEV}_{1}$ in PFT; $\% \mathrm{FEV}_{1}$ of ipsilateral preserved lobe $=$ (radioactivity of ipsilateral preserved lobe/radioactivity of whole lung $\times \% \mathrm{FEV}_{1}$ in PFT; and $\% \mathrm{FEV}_{1}$ of the contralateral lung $=$ (radioactivity of contralateral lung/radioactivity of whole lung) $\times \% \mathrm{FEV}_{1}$ in PFT.

\section{Calculation of Postoperative Changes of Regional Lung Function and Predicted Postoperative Pulmonary Function}

Postoperative changes of ipsilateral preserved lobe and contralateral lung functions were calculated as follows: (1) $\Delta \% \mathrm{FEV}_{1}$ of ipsilateral preserved lobe $=\% \mathrm{FEV}_{1}$ of ipsilateral preserved lobe after surgery $-\% \mathrm{FEV}_{1}$ of

TABLE 1. Standardized mean differences of variables included in the matching

\begin{tabular}{|c|c|c|c|c|c|c|}
\hline & \multicolumn{3}{|c|}{ Before matching } & \multicolumn{3}{|c|}{ After matching } \\
\hline & $\overline{\text { ICRT }(n=64)}$ & Non-ICRT $(n=141)$ & SMD & ICRT $(n=46)$ & Non-ICRT $(n=46)$ & SMD \\
\hline Age, y & $68[63-75]$ & $67[62-73]$ & 0.224 & $67[63-73]$ & 70 [62-74] & 0.067 \\
\hline Smoking, pack-years & $35[0-55]$ & $40[23-54]$ & -0.091 & $42[0-74]$ & $43[24-57]$ & 0.045 \\
\hline \multicolumn{7}{|l|}{ Pulmonary function } \\
\hline $\mathrm{FEV}_{1} / \mathrm{FVC}$ & $0.73[0.66-0.77]$ & $0.68[0.62-0.74]$ & 0.39 & $0.69[0.59-0.76]$ & $0.69[0.64-0.73]$ & -0.064 \\
\hline$\% \mathrm{FEV}_{1}$ & 107 [95-120] & 99 [88-109] & 0.412 & 103 [89-119] & $102[92-112]$ & -0.056 \\
\hline Predicted $\% \mathrm{FEV}_{1}$ after surgery & 86 [75-97] & 83 [74-93] & 0.097 & 87 [74-99] & 83 [74-94] & -0.056 \\
\hline \multicolumn{7}{|l|}{ Lobe } \\
\hline RUL & 20 & 40 & 0.596 & 17 & 17 & 0 \\
\hline RML & 4 & 21 & & 4 & 4 & \\
\hline RLL & 9 & 29 & & 8 & 8 & \\
\hline LUL & 20 & 22 & & 11 & 11 & \\
\hline LLL & 6 & 26 & & 5 & 5 & \\
\hline RML + RLL & 5 & 3 & & 1 & 1 & \\
\hline
\end{tabular}

Data are presented as median [interquartile range] or $\mathrm{n}$ except where otherwise stated. ICRT, Induction chemoradiotherapy; $S M D$, standardized mean difference; $F E V_{l}$, forced expiratory volume in 1 second; $F V C$, forced vital capacity; $R U L$, right upper lobe; $R M L$, right middle lobe; $R L L$, right lower lobe; $L U L$, left upper lobe; $L L L$, left lower lobe. 


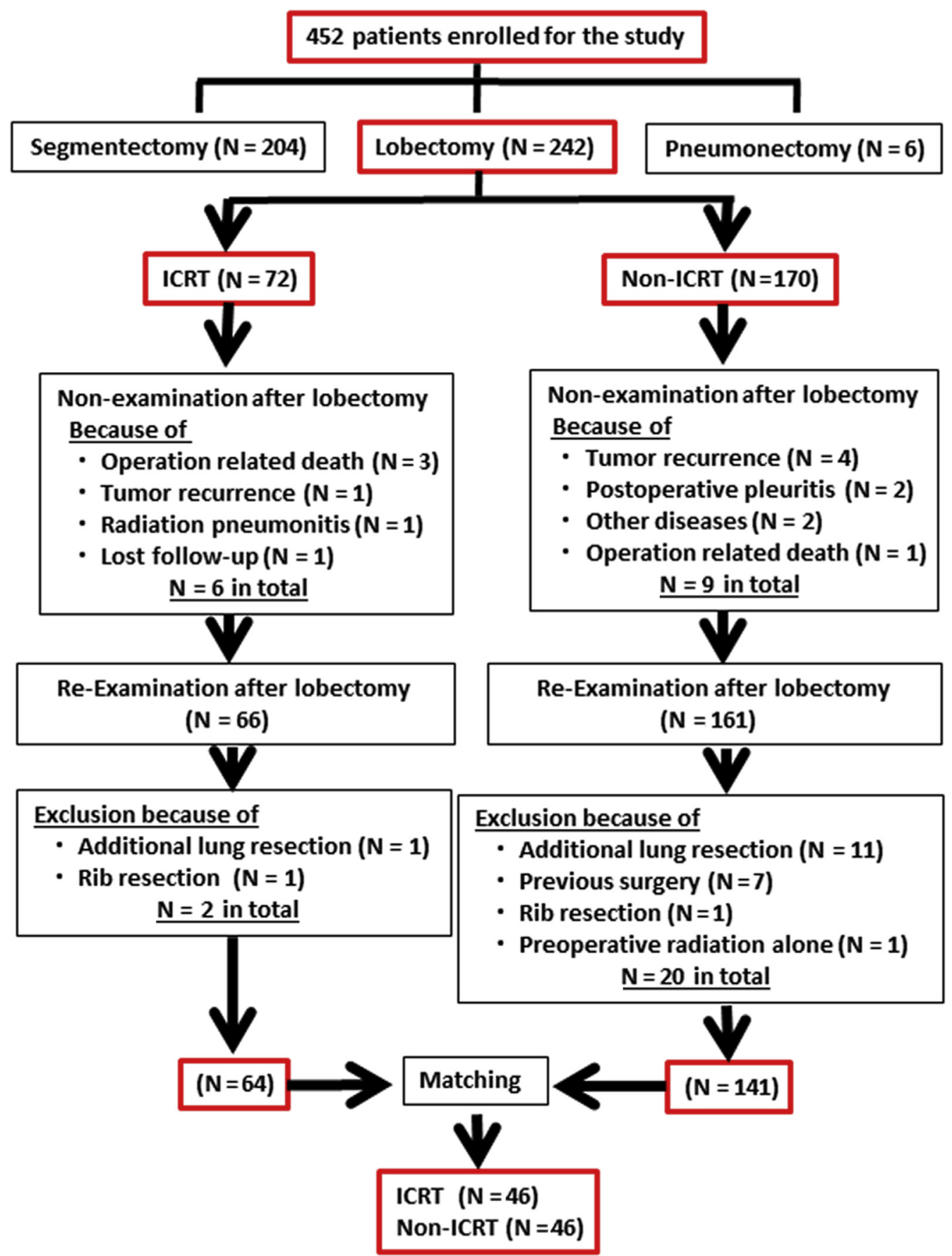

FIGURE 1. Patient algorithm used in the study. ICRT, Induction chemoradiotherapy.

ipsilateral preserved lobe before surgery, and (2) $\Delta \% \mathrm{FEV}_{1}$ of contralateral lung $=\% \mathrm{FEV}_{1}$ of contralateral lung after surgery $-\% \mathrm{FEV}_{1}$ of contralateral lung before surgery. Predicted postoperative pulmonary function was calculated using the following formula: $\left(\% \mathrm{FEV}_{1}\right.$ of whole-lung before surgery $-\% \mathrm{FEV}_{1}$ of resected lobe).

\section{Statistical Analysis}

A logistic regression analysis was used to compute the propensity score for the selection of ICRT and non-ICRT groups from the pretreatment variables, including age, smoking history (pack-years), $\% \mathrm{FEV}_{1}$ and $\mathrm{FEV}_{1} / \mathrm{FVC}$, which have been reported to associate with postoperative whole-lung function (ie, the primary outcome). ${ }^{21,22}$ In addition, predicted postoperative pulmonary function was included for the propensity score estimation, regardless of the value calculated from the SPECT data, to clarify the chronic effect of ICRT on lung function after lobectomy. The propensity score estimation did not include potential confounders including sex, tumor size, comorbidity index, postoperative adjuvant chemotherapy, resected lobe $\% \mathrm{FEV}_{1}$, ipsilateral preserved lobe 


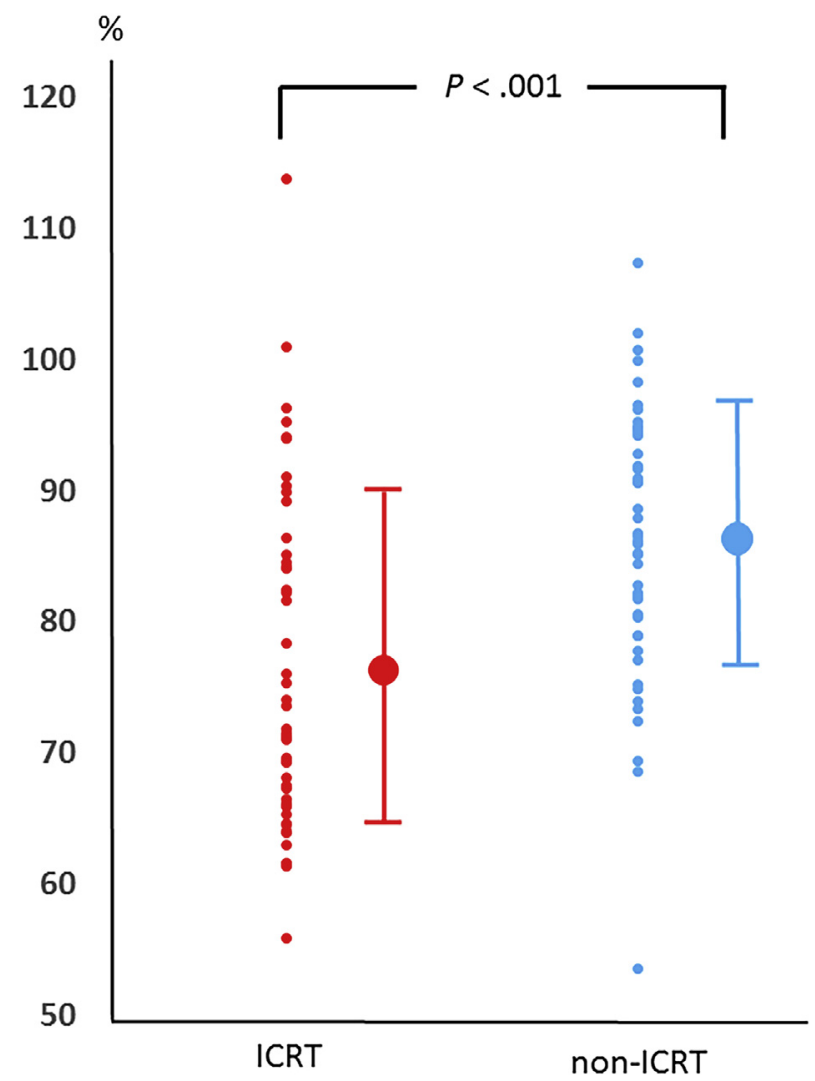

FIGURE 2. Percentages of postoperative versus preoperative whole-lung function in the induction chemoradiotherapy (ICRT) and non-ICRT groups. The postoperative change of whole-lung function, evaluated from the formula $\% \mathrm{FEV}_{1}$ in PFT after surgery $/ \% \mathrm{FEV}_{1}$ before surgery. Red indicates the postoperative change of whole-lung function in ICRT group, and blue indicates the postoperative change of whole-lung function in non-ICRT group.

$\% \mathrm{FEV}_{1}$, contralateral lung $\% \mathrm{FEV}_{1}$ and clinical $\mathrm{N}$-factor, because those variables have no evidence to associate with postoperative pulmonary function. However, to test the robustness of the primary analysis, multivariable linear regression analysis was conducted for those potential confounders to assess the association of ICRT to the primary outcome after the matching. Propensity score matching with an exact matching on the resected lobe site selected 1:1 matched subjects from the 2 groups without replacement. Match balance between the groups were assessed with standardized mean differences of variables included in the propensity score estimation and was considered appropriate if none of the absolute standardized mean differences exceeded 0.1. Allowable calipers used for the matching were 0.2 multiplied SD of logit transformed propensity score. Differences of values between the 2 groups and differences between preoperative and postoperative values in each group were analyzed using Wilcoxon singed rank test. In the ICRT group, the difference between preoperative PFT data before and after ICRT was analyzed using Wilcoxon signed rank test. Values of $P<.05$ were accepted as significant. The matching analysis and sensitivity analysis was done using $\mathrm{R}$ 3.3.2 statistical analysis software (R Foundation for Statistical Computing, Vienna, Austria), and all of the other analyses were done using SPSS version 24.0 software (IBM Corp, Armonk, NY). Descriptive statistics and predictive statistics in the text and in Table 1 are given as mean $\pm \mathrm{SD}$ and $95 \%$ CI.

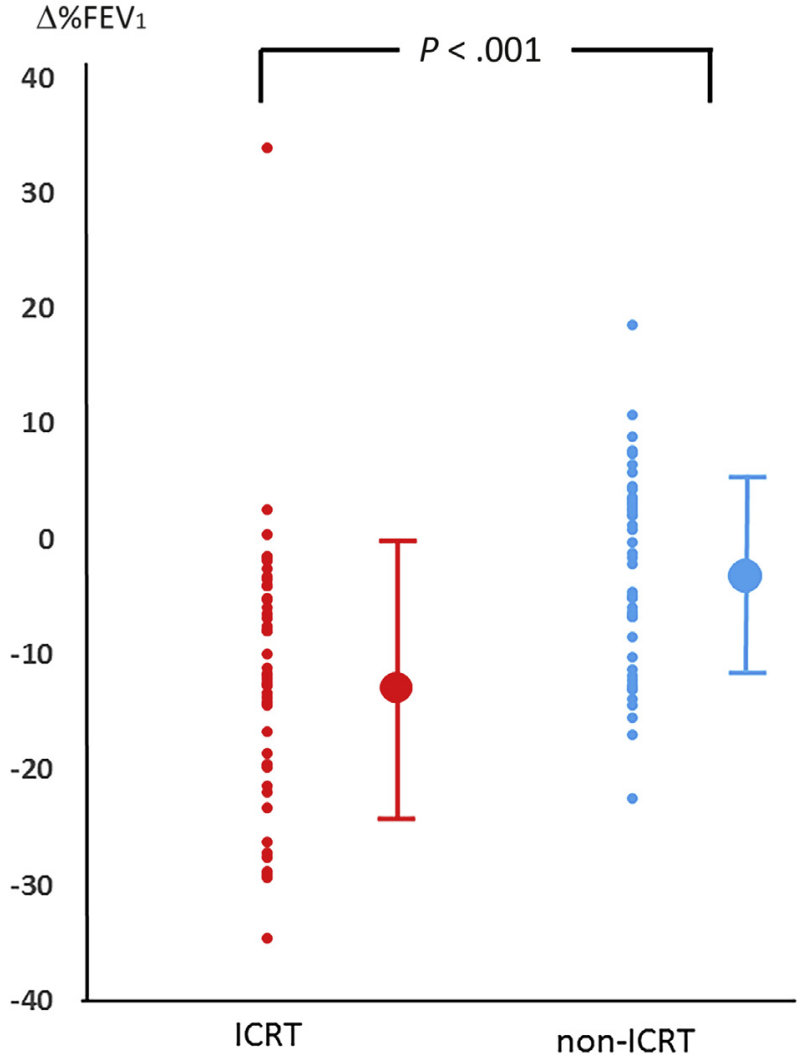

FIGURE 3. $\Delta \%$ forced expiratory volume in 1 second $\left(F E V_{l}\right)$ of the ipsilateral preserved lobe after surgery in the induction chemoradiotherapy (ICRT) and non-ICRT groups. The postoperative change of whole-lung function, evaluated from the formula $\% \mathrm{FEV}_{1}$ in $\mathrm{PFT}$ after surgery/ $\% \mathrm{FEV}_{1}$ before surgery. Red indicates the postoperative change of whole-lung function in ICRT group, and blue indicates the postoperative change of whole-lung function in non-ICRT group.

\section{RESULTS}

During the study duration, 452 patients with lung cancer, who were treated with segmentectomy $(\mathrm{n}=204)$, lobectomy $(\mathrm{n}=242)$, or pneumonectomy $(\mathrm{n}=6)$, were planned to be examined using preoperative and postoperative PFT and perfusion SPECT/CT (Figure 1). Preoperative SPECT perfusion was conducted by $16 \pm 11$ days (95\% CI, 13-19) before surgery. Of the 242 patients treated with lobectomy, 72 were treated with ICRT (ICRT group) and 170 were not (non-ICRT group). The reason for the high incidence of ICRT in the lobectomy group (ie, 72 of 242 patients; $30 \%$ ), came from the large number of segmentectomy $(\mathrm{n}=204)$ for cT1N0M0 NSCLC in our hospital. Of the lobectomy patients, 64 patients in the ICRT group and 141 patients in the non-ICRT group were candidates for the matching analysis. A propensity score matching with exact matching on lobe site selected each 46 patients from the ICRT and non-ICRT groups (Table 1). Standardized differences plots to show the change 


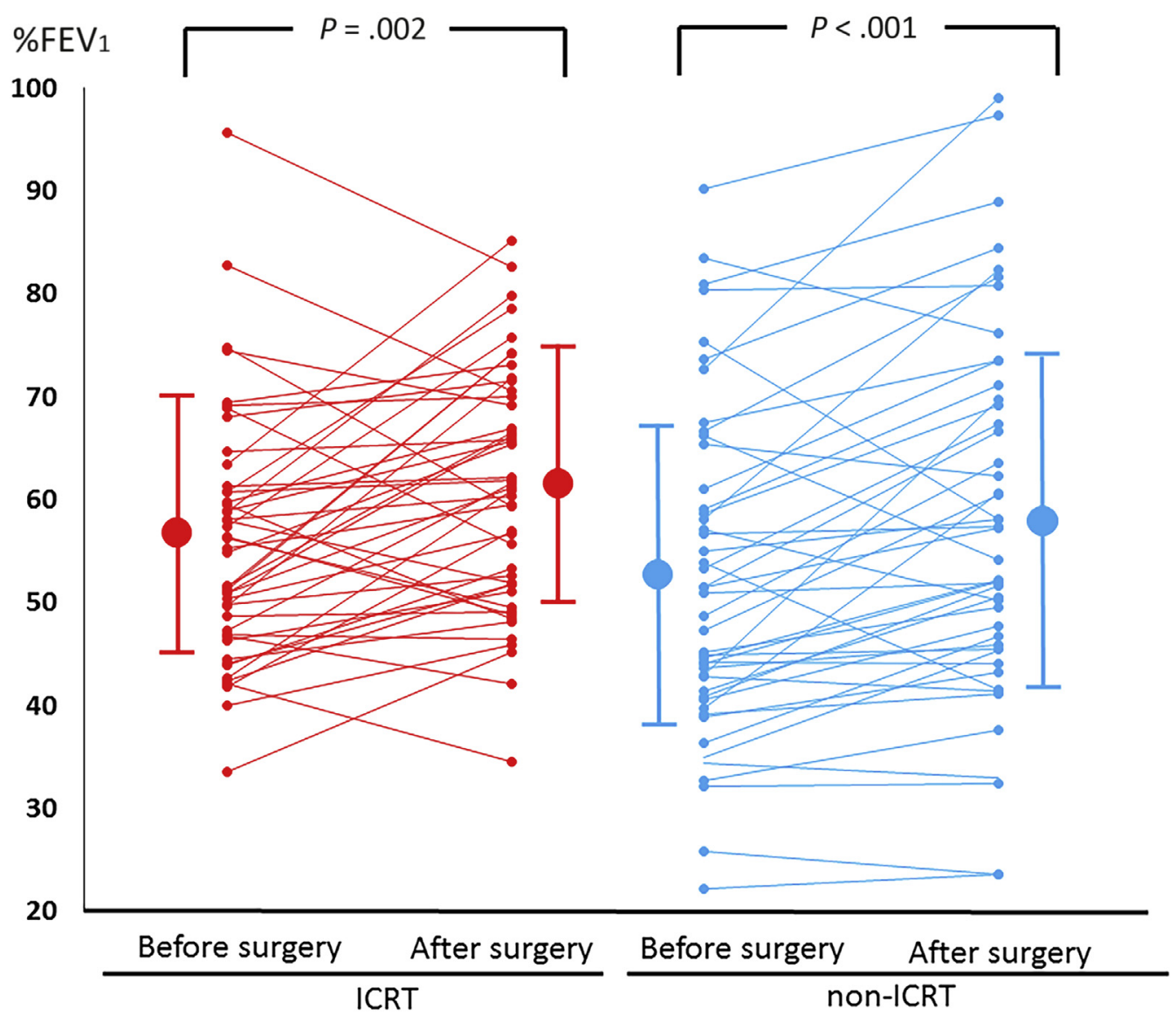

FIGURE 4. Preoperative and postoperative percentage of forced expiratory volume in 1 second $\left(F E V_{1}\right)$ values of the contralateral lung in the induction chemoradiotherapy (ICRT) and non-ICRT groups.

in standardized difference for each variable before and after matching are shown in Figure E1. Mirror histograms for the propensity scores to show the region of common support between the groups is shown in Figure E2. All of the absolute standardized mean differences in matched variables were $<0.1$. Tumor size was $4.5 \pm 1.8 \mathrm{~cm}(95 \% \mathrm{CI}, 4.0-5.0)$ in the ICRT group, which was significantly larger than $3.4 \pm 2.2 \mathrm{~cm}(95 \%$ CI, 2.7-4.1) in the non-ICRT group $(P=.003)$. Regarding clinical $\mathrm{N}$-stage, the ICRT group had N0 in 9 patients, N1 in 14, N2 in 20, and N3 in 3, whereas the non-ICRT group had N0 in 40, N1 in 5, and N2 in 1. The ICRT group had fewer N0 stage than the non-ICRT group with significance $(P<.001)$.

In the ICRT group, the radiation dose was $40 \mathrm{~Gy}$ in 25 patients, 46 Gy in 20 , and 50 Gy in 1 . The dose volume histogram parameters are the following: (1) mean lung dose on the whole lung was $9.1 \pm 2.6$ Gy $(95 \%$ CI, 8.3-9.9), and (2) percentages of the lung volume (with subtraction of the volume involved by lung cancer) that receives radiation doses of $20 \mathrm{~Gy}$ or more (V20) and 5 Gy or more (V5) were $19.0 \pm 6.9 \%$ (95\% CI, 16.9-21.1) and
$30.0 \% \pm 9.6 \% \quad(95 \%$ CI, 27.3-33.2), respectively. Although 1 of the 46 patients ( $2 \%$ ) received V20 $\geq 30 \%$, none of the patients received the levels of V $5 \geq 70 \%$ or mean lung dose $\geq 20 \mathrm{~Gy}$, which are risk levels for radiation pneumonitis according to the National Comprehensive Cancer Network Guidelines. Although none of the 46 patients suffered radiation pneumonitis before surgery, 2 patients (4\%) suffered radiation pneumonitis with grade 2 after surgery. One of the 2 patients required steroid therapy, and was treated with oral prednisolone $1 \mathrm{mg} / \mathrm{d}$ at 6 months after surgery, when the postoperative PFT and SPECT/CT were conducted. Although 23 of the 46 patients $(50 \%)$ in the ICRT group and 10 of the 46 patients $(22 \%)$ in the non-ICRT group were treated with postoperative adjuvant chemotherapy, none of the patients received the chemotherapy at 6 months after surgery.

In the ICRT group, the preoperative $\% \mathrm{FEV}_{1}$ values before and after ICRT were $103 \% \pm 20 \%(95 \% \mathrm{CI}$, 98-109) and $102 \% \pm 20 \%$ (95\% CI, 96-109), respectively, and the difference was not significant $(P=.37)$. The preoperative $\mathrm{FEV}_{1} / \mathrm{FVC}$ values before and after ICRT were $0.68 \% \pm 0.09 \% \quad(95 \% \quad \mathrm{CI}, \quad 0.65-0.71)$ and 


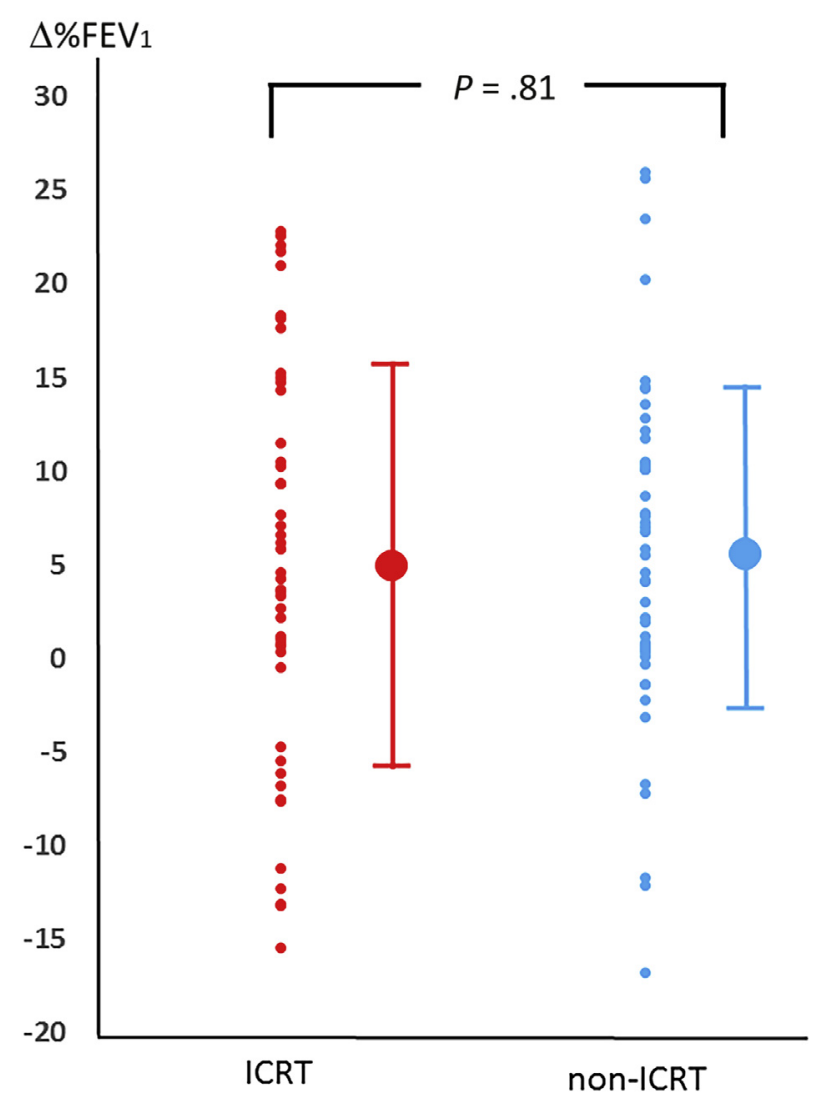

FIGURE 5. $\Delta \%$ forced expiratory volume in 1 second $\left(F E V_{1}\right)$ of the contralateral lung after surgery in the induction chemoradiotherapy (ICRT) and non-ICRT groups. The postoperative change of whole-lung function, evaluated from the formula $\% \mathrm{FEV}_{1}$ in PFT after surgery/ $\% \mathrm{FEV}_{1}$ before surgery. Red indicates the postoperative change of whole-lung function in ICRT group, and blue indicates the postoperative change of whole-lung function in non-ICRT group.

$0.69 \% \pm 0.09 \%(95 \% \mathrm{CI}, 0.66-0.71)$, respectively, and the difference was not significant $(P=.36)$.

Figure 2 shows the postoperative change of whole-lung function (ie, $77 \% \pm 13 \% ; 95 \% \mathrm{CI}, 73-80$ ) in the ICRT group and $86 \% \pm 10 \%(95 \% \mathrm{CI}, 83-89)$ in the non-ICRT group. The ICRT group showed a significant lower value than the non-ICRT group $(P<.001)$.

The $\% \mathrm{FEV}_{1}$ values of the resected lobe were $17 \% \pm 8 \%$ (95\% CI, 14-19) in the ICRT group and $18 \% \pm 8 \%(95 \%$ CI, 16-20) in the non-ICRT group, and the difference was not significant $(P=.28)$. The $\% \mathrm{FEV}_{1}$ values of the ipsilateral preserved lobe before surgery were $30 \% \pm 11 \%(95 \% \mathrm{CI}, 27-34)$ in the ICRT group and $33 \% \pm 12 \%$ (95\% CI, 29-36) in the non-ICRT group, with no significant difference $(P=.33)$.

Figure 3 shows the $\Delta \% \mathrm{FEV}_{1}$ of the ipsilateral preserved lobe ie, $-12 \% \pm 12 \% ; 95 \%$ CI, -15 to -8 ) in the ICRT group, and $-3 \% \pm 9 \%(95 \% \mathrm{CI},-5$ to 0$)$ in the non-ICRT group. The ICRT group showed a significant decrease in the ipsilateral preserved lobe function after surgery than the non-ICRT group $(P<.001)$.

Figure 4 shows the preoperative and postoperative \% $\mathrm{FEV}_{1}$ values of contralateral lung in each group. In the ICRT group, the preoperative and postoperative values were $56 \% \pm 12 \%(95 \% \mathrm{CI}, 52-59)$ and $61 \% \pm 12 \%$ (95\% CI, 57-64), respectively. In the non-ICRT group, the preoperative and postoperative values were $53 \% \pm 15 \%(95 \%$ CI, 48-57) and 58\% $\pm 17 \%$ (95\% CI, 53-63), respectively. The ICRT as well as non-ICRT groups showed a significant increase of contralateral lung function after surgery $(P=.002$ and $P<.001$, respectively). Figure 5 shows the $\Delta \% \mathrm{FEV}_{1}$ of the contralateral lung (ie, $5 \% \pm 11 \% ; 95 \% \mathrm{CI}, 2-8$ ) in the ICRT group and $6 \% \pm 9 \%(95 \% \mathrm{CI}, 3-8)$ in the non-ICRT group, and the difference was not significant $(P=.81)$. Figure 6 shows the sensitivity analysis to test the robustness of the primary analysis, indicating that the associations of ICRT and the primary outcome were almost consistent after adjustment of the 8 potential confounders, including sex, tumor size, comorbidity index, postoperative chemotherapy, resected lobe $\% \mathrm{FEV}_{1}$, ipsilateral preserved lobe $\% \mathrm{FEV}_{1}$, contralateral lung $\% \mathrm{FEV}_{1}$, and clinical $\mathrm{N}$-factor.

\section{DISCUSSION}

The present study showed the following points: (1) the ICRT group showed that the decrease of postoperative whole lung function in the ICRT group was significantly larger than that in the non-ICRT group; (2) although the ipsilateral preserved lobe function before surgery was not different between the 2 groups, the ICRT group showed a significant decrease after lobectomy than the non-ICRT group; and (3) although the contralateral lung function increased significantly after lobectomy in both groups, the increases were not different between the 2 groups.

The present study showed that ICRT decreased pulmonary function after lobectomy, which was caused by the significant decrease of ipsilateral preserved lobe function. It is well known that radiation therapy for lung cancer damages normal lung tissue around the tumor. The dose volume histogram parameters, such as V20, V5, and mean lung dose, have been reported to be associated with not only a risk of radiation pneumonitis but also a decrease of whole-lung function 6 months after definitive chemoradiotherapy. ${ }^{23}$ Although those parameters were lower than the risk levels for radiation pneumonitis in the present study, the ipsilateral preserved lobe function significantly decreased during 6 months after lobectomy in the ICRT group, which could be caused by chronic and subclinical lung injury by ICRT. The decrease of postoperative whole-lung function was approximately $10 \%$ lower in the ICRT group than in the non-ICRT group, as shown in Figure 2. We should keep in mind that ICRT 
Models

A. Original model

B. A. $+\operatorname{sex}$

C. A. + tumor size

D. A. + comorbidity index

E. A. + postoperative chemotherapy

F. A. + resected lobe $\% F E V_{1}$

G. A. + ipsilateral non-resected lobe $\% F E V_{1}$

H. A. + contralateral lung \% FEV

I. A. + TNM classification $\mathrm{N}$ factor

J. A. + all the potential confounders

Difference in the primary outcome (\%)

$$
\begin{aligned}
& -9.4[-14.3,-4.6] \\
& -9.0[-13.9,-4.1] \\
& -9.9[-15.0,-4.9] \\
& -10.3[-14.9,-5.7] \\
& -10.4[-15.4,-5.3] \\
& -9.8[-14.6,-5.0] \\
& -9.0[-13.8,-4.2] \\
& -8.9[-13.8,-4.1] \\
& -6.8[-13.5,-0.0] \\
& -9.2[-15.7,-2.6]
\end{aligned}
$$

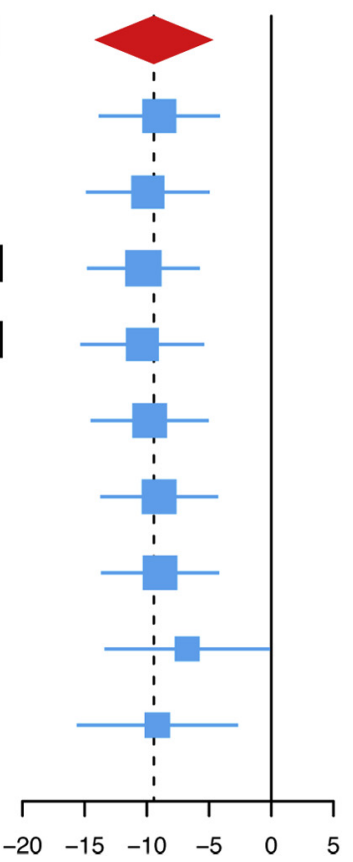

FIGURE 6. Sensitivity analyses for potential confounders. Intergroup comparison of the primary outcome after propensity score matching (original model) was further adjusted for each potential confounder (model B-I) and all potential confounders (model J). Estimates are shown in mean difference with $95 \%$ confidence intervals. $\% F E V_{1}$, Percentage of predicted forced expiratory volume in 1 second.

would decrease postoperative pulmonary function $10 \%$ more than anticipated.

Although the postoperative change of the contralateral lung function was not significantly different between the ICRT and non-ICRT groups, the contralateral lung function significantly increased after lobectomy in both groups as shown in Figures 4 and 5 (ie, approximately 5\% increase). It has been reported that pulmonary function after lung resection is usually higher than predicted value. ${ }^{9,24}$ This phenomenon has been confirmed after pneumonectomy in mice, which causes lung expansion and an alveolar increase in the contralateral lung ${ }^{25,26}$; it is referred to as "compensatory lung growth." Although the patients in the present study were treated with lobectomy not pneumonectomy, our data showed that compensatory lung growth also occurred after lobectomy on the contralateral lung, even after ICRT.

The limitations of the present study are as follows: (1) we could only match the confounders, for which there is evidence of association with postoperative pulmonary function, for making a sufficient match balance, (2) of the potential confounders that were not used for matching, the tumor size and $\mathrm{N}$-stage might directly affect the resected lobe function causing the difference of postoperative pulmonary function between the groups, but they could not be matched because of complete different treatment indications for tumor stage between the groups,
(3) preoperative SPECT lung perfusion in the ICRT group was conducted only after ICRT but not before ICRT, which did not allow us to address the short-term effects of ICRT before surgery, (4) survival bias between the groups (ie, whereas 3 patients in the ICRT group [4\%] suffered surgery-related death, only 1 in the non-ICRT group $[0.6 \%]$ died), and (5) DLCO was not examined in the present study, which has been reported to be a more sensitive measure of lung injury by ICRT than PFT. ${ }^{6-8}$ Regarding the first issue, the sensitivity analysis showed consistent results for the potential confounders, which were excluded from the matching. Regarding the second issue, the sensitivity test showed that the adjustments of tumor size and $\mathrm{N}$-factor did not change the associations of ICRT and the primary outcome. In the present study, we matched the predicted postoperative pulmonary function between the 2 groups, which made the resected lobe function similar between the 2 groups. We consider that matching the predicted postoperative pulmonary function between the groups would decrease the effect of the tumor size and clinical $\mathrm{N}$-factor for the primary outcome. Regarding the third issue, because preoperative pulmonary functions were not different between the values before and after ICRT, we suppose that preoperative lung perfusion would also be similar between the pre- and post-ICRT conditions. Regarding the fourth issue (ie, survival bias), because the cause of death 
would associate with decreasing postoperative pulmonary function, the exclusion of the dead patients in the ICRT group would not affect the primary outcome.

\section{CONCLUSIONS}

ICRT was associated with reduced pulmonary function after lobectomy due to decrease in the ipsilateral preserved lobe function caused by the chronic effect of ICRT. Although ICRT is a useful treatment for improving survival in locally advanced lung cancer patients, we should keep in mind that it significantly decreases pulmonary function after lobectomy $10 \%$ more than anticipated.

\section{Conflict of Interest Statement}

Authors have nothing to disclose with regard to commercial support.

\section{References}

1. Albain KS, Swann RS, Rusch VW, Turrisi AT III, Shepherd FA, Smith C, et al. Radiotherapy plus chemotherapy with or without surgical resection for stage III non-small-cell lung cancer: a phase III randomized controlled trial. Lancet. 2009; 374:379-86.

2. Rusch VW, Giroux DJ, Kraut MJ, Crowley J, Hazuka M, Winton T, et al. Induction chemoradiation and surgical resection for superior sulcus non-small-cell lung carcinomas: long-term results of Southwest Oncology Group Trial 9416 (Intergroup Trial 0160). J Clin Oncol. 2007;25:313-8.

3. Kunitoh H, Kato H, Tsuboi M, Shibata T, Asamura H, Ichinose Y, et al. Phase II trial of preoperative chemoradiotherapy followed by surgical resection in patients with superior sulcus non-small-cell lung cancers: report of Japan Clinical Oncology Group trial 9806. J Clin Oncol. 2008;26:644-9.

4. Kawaguchi K, Yokoi K, Niwa H, Ohde Y, Mori S, Okumura S, et al. Trimodality therapy for lung cancer with chest wall invasion: initial results of a phase II study. Ann Thorac Surg. 2014;98:1184-91.

5. Eberhardt WE, Pöttgen C, Gauler TC, Friedel G, Veit S, Heinrich V, et al. Phase III study of surgery versus definitive concurrent chemoradiotherapy boost in patients with resectable stage IIIA (N2) and selected IIIB non-small-cell lung cancer after induction chemotherapy and concurrent chemoradiotherapy (ESPATUE). J Clin Oncol. 2015;33:4194-201.

6. Perentes J, Bopp S, Krueger T, Gonzalez M, Jayet PY, Lovis A, et al. Impact of lung function changes after induction radiochemotherapy on resected T4 non-small cell lung cancer outcome. Ann Thorac Surg. 2012;94:1815-22.

7. Cerfolio RJ, Talati A, Bryant AS. Changes in pulmonary function tests after neoadjuvant therapy predict postoperative complications. Ann Thorac Surg. 2009;88:930-5.

8. Margaritora S, Cesario A, Cusumano G, Cafarotti S, Corbo GM, Ferri L, et al. Is pulmonary function damaged by neoadjuvant lung cancer therapy? A comprehensive serial time-trend analysis of pulmonary function after induction radiochemotherapy plus surgery. J Thorac Cardiovasc Surg. 2010;139:1457-63.

9. Zeiher BG, Gross TJ, Kern JA, Lanza LA, Peterson MW. Predicting postoperative pulmonary function in patients undergoing lung resection. Chest. 1995;108:68-72.
10. Wu MT, Pan HB, Hsu HK, Hsu HK, Chang HC, Peng NJ, et al. Prediction of postoperative lung function in patients with lung cancer: comparison of quantitative CT with perfusion scintigraphy. Am J Roentgenol. 2002;178:667-72.

11. Yoshimoto K, Nomori H, Mori T, Kobayashi H, Ohba Y, Shibata H, et al Quantification the impact of segmentectomy on pulmonary function by perfusion SPECT/CT. J Thorac Cardiovasc Surg. 2009;137:1200-5.

12. Yoshimoto K, Nomori H, Mori T, Kobayashi H, Ohba Y, Shibata H, et al. Prediction of pulmonary function after lung lobectomy by subsegments counting, computed tomography, single photon emission computed tomography and computed tomography: a comparative study. Eur J Cardiothorac Surg. 2009; $35: 408-13$.

13. Nomori H, Horio H, Suemasu K. Anterior limited thoracotomy with intrathoracic illumination for lung cancer: its advantages over anteroaxillary and posterolateral thoracotomy. Chest. 1999;115:874-80.

14. Nomori H, Ohtsuka T, Horio H, Naruke T, Suemasu K. Difference in the impairment of vital capacity and 6-minute walking after a lobectomy performed by thoracoscopic surgery, an anterior limited thoracotomy, an anteroaxillary thoracotomy, and a posterolateral thoracotomy. Surg Today. 2003;33:7-12.

15. Japan Lung Cancer Society. Guidelines for Lung Cancer. Tokyo, Japan: Kanehara Press; 2014.

16. Goldstraw P, ed. IASLC Staging Manual in Thoracic Oncology. Orange Park, FL Editorial Rx Press; 2009.

17. Nomori H, Horio H, Fuyuno G, Kobayashi R. Non-serratus-sparing antero-axillary thoracotomy with disconnection of anterior rib cartilage. Chest. 1997;111:572-6.

18. Nomori H, Cong Y, Sugimura H. Limited thoracotomy for segmentectomy: a comparison of postoperative pain with thoracoscopic lobectomy. Surg Today. 2016;46:1243-8.

19. Berglund E, Birath G, Bjure J, Grimby G, Kjellmer I, Sandqvist L, et al Spirometric studies in normal subjects. I. Forced expirograms in subjects between 7 and 70 years of age. Acta Med Scand. 1963;173:185-92.

20. Nomori H, Cong Y, Sugimura H. Systemic and regional pulmonary function after segmentectomy. J Thorac Cardiovasc Surg. 2016;152:747-53.

21. Takahashi Y, Matsutani N, Morita S, Dejima H, Nakayama T, Uehara H, et al Predictors of long-term compensatory response of pulmonary function following major lung resection for non-small cell lung cancer. Respirology. 2017;22: 364-71.

22. Nomori H, Horio H, Fuyuno G, Kobayashi R, Yashima H. Respiratory muscle strength after lung resection with special reference to age and procedures of thoracotomy. Eur J Cardiothorac Surg. 1996;10:352-8.

23. Park YH, Kim JS. Predictors of radiation pneumonitis and pulmonary function changes after concurrent chemoradiotherapy of non-small cell lung cancer Radiat Oncol J. 2013;31:34-40

24. Ueda K, Tanaka T, Hayashi M, Li TC, Tanaka N, Hamano K. Computed tomography-defined functional lung volume after segmentectomy versus lobectomy. Eur J Cardiothorac Surg. 2010;37:1433-7.

25. Takahashi Y, Izumi Y, Kohno M, Kimura T, Kawamura M, Okada Y, et al Thyroid transcription factor-1 influences the early phase of compensatory lung growth in adult mice. Am J Respir Crit Care Med. 2010;181:1397-406.

26. Takahashi Y, Izumi Y, Kohno M, Kawamura M, Ikeda E, Nomori H. Airway administration of dexamethasone, 3'-5'-cyclic adenosine monophosphate, and isobutylmethylxanthine facilitates compensatory lung growth in adult mice. Am J Physiol Lung Cell Mol Physiol. 2011;300:L453-61.

Key Words: lung cancer, induction chemoradiotherapy, pulmonary function, lobectomy, perfusion scintigraphy 


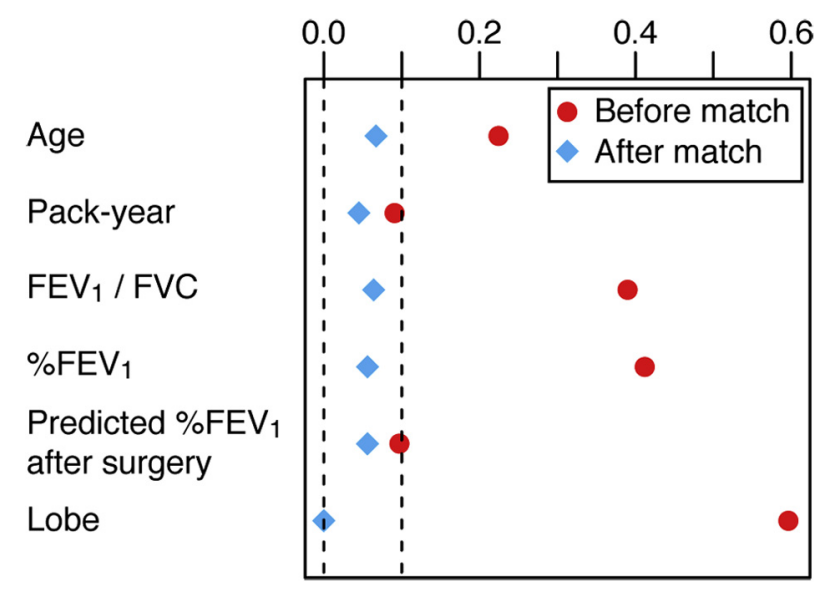

FIGURE E1. Absolute standardized mean differences between the control group and chemoradiotherapy group before and after matching. $F E V_{1}$, Forced expiratory volume in 1 second; $F V C$, forced vital capacity.

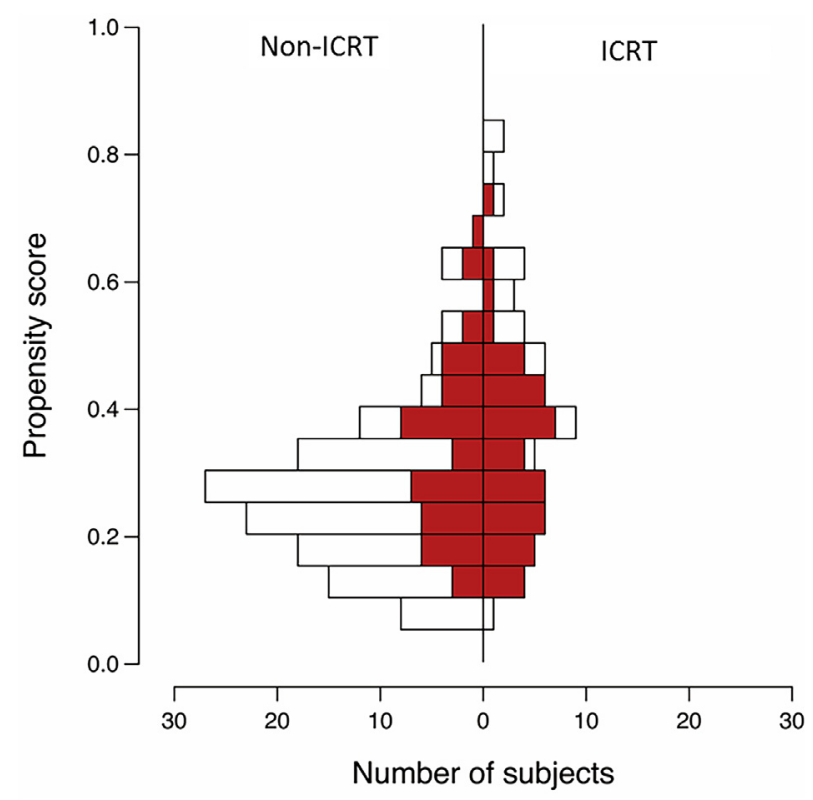

FIGURE E2. Distribution of the propensity score in the induction chemoradiotherapy (ICRT) as well as the non-ICRT groups before and after matching is shown as a histogram per $5 \%$ propensity score steps; white bars, before the matching; red bars, after the matching. 